\section{Commentary: Don't sweat the small stuff}

\author{
Bartley P. Griffith, MD, FACS, FRCS
}

Richard Carlson, author of Don't Sweat the Small Stuff... and It's All Small Stuff, ${ }^{1}$ died from pulmonary embolism during a flight from San Francisco to New York, a fact particularly cogent to the report by de Perrot and colleagues. $^{2}$ de Perrot and colleagues ${ }^{2}$ confirm the work of others in their retrospective review of 401 patients accrued between 2005 and 2020. ${ }^{3,4}$ They show that lone distal segmental and subsegmental small vessel arteriopathy is treatable by pulmonary thromboendoarterectomy with low operative mortality $(2.7 \%)$ compared with outcomes with proximal disease $(2.3 \%)$. Their original contribution is principally to alert us to the need for continued follow-up of postoperative chronic thromboembolic pulmonary hypertension patients, particularly those with segmental disease. Although $20 \%$ of patients with main and lobar disease required medical therapy for pulmonary hypertension, $38 \%$ with segmental disease required targeted therapy. This is important because, with increasing experience with pulmonary thromboendoarterectomy, indication for distal disease now has increased from $7 \%$ to $41 \%$ over the past 5 years. Although 5-year survival was reduced for those with distal disease, they did achieve an excellent $80 \%$ versus $91 \%$ 5-year survival.

I have always found the decision to operate on segmental disease - and, at times, the accurate diagnosis of the distal arteriopathy-to be stressful. When I open into main and intermediate pulmonary arteries that have no thrombus or proximal lobar obstructions, I blink fast

\footnotetext{
From the Division of Cardiac Surgery, Department of Surgery, University of Maryland School of Medicine, Baltimore, Md.

Disclosures: The author reported no conflicts of interest.

The Journal policy requires editors and reviewers to disclose conflicts of interest and to decline handling or reviewing manuscripts for which they may have a conflict of interest. The editors and reviewers of this article have no conflicts of interest.

Received for publication Nov 16, 2021; revisions received Nov 16, 2021; accepted for publication Nov 17, 2021; available ahead of print Nov 20, 2021.

Address for reprints: Bartley P. Griffith, MD, FACS, FRCS, Division of Cardiac Surgery, Department of Surgery, University of Maryland School of Medicine, $110 \mathrm{~S}$ Paca St, 7th Floor, Baltimore, MD 21201 (E-mail: bgriffith@som.umaryland.edu). J Thorac Cardiovasc Surg 2022;164:708-9 $0022-5223 / \$ 36.00$

Copyright $₫ 2021$ Published by Elsevier Inc. on behalf of The American Association for Thoracic Surgery

https://doi.org/10.1016/j.jtcvs.2021.11.035
}

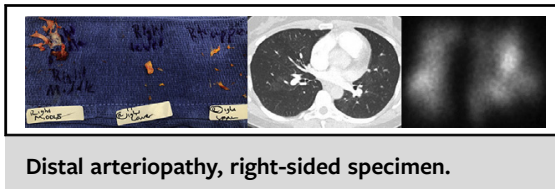

CENTRAL MESSAGE

Segmental arteriopathy associated with distal lesions of CTEPH are amenable to surgical removal. Patients prone toward postoperative pulmonary hypertension require adjuvant vasodilator therapy.

to deflect the white light of my headlamp, which bounces back from the diaphanous intima. With circulatory arrest and the quickened pulse of the 10- to 15-minute near bloodless field, I am comforted to find the same distal intimal thickening from which a plane of dissection can be established, webs, and obstructions that the authors describe. The multiple bits of surgical specimens from the segmental arteries do not draw the approbation of the operating room team like the trunk and branch large thrombofibrous ones removed from lobar and main arteries. Sometimes it seems that removal of the small stuff can indeed pay dividends to quality of life and survival. Don't sweat the small distal specimens, but learn how to efficiently work from deeply within and to cherish the more menial obstructing proceeds from the darker recesses. The postoperative reductions in total pulmonary resistance, which nears those achieved in proximal disease, affirms the physiological significance of the distal arteriopathy and the value of their removal. Perhaps balloon angioplasty might be underutilized for the distal disease..$^{5}$

I wonder how best to diagnose distal disease. de Perrot and colleagues ${ }^{2}$ do not dwell on this, and I know it to be nuanced. At Maryland, I am fortunate to have a chronic thromboembolic pulmonary hypertension team to help guide decisions. Experience is drawn from nuclear medicine, diagnostic chest radiography, interventional pulmonology, cardiology, and interventional radiology. We seek a good history, confirming echocardiograph, significant peripheral irregularities on perfusion scans, and on computed tomography webs, ostial cutoffs, withering irregular distal arteries, and losses of regional blood flow... and it's all small stuff. 


\section{References}

1. Carlson R. Don't Sweat the Small Stuff...and It's All Small Stuff: Simple Ways to Keep the Little Things from Taking Over Your Life. Hachette Books; 1997.

2. de Perrot M, Donahoe L, McRae K, Thenganatt J, Moric J, Chan J, et al. Outcome after pulmonary endarterectomy for segmental chronic thromboembolic pulmonary hypertension. J Thorac Cardiovasc Surg. 2022;164: 696-707.e4.
3. Jamieson SW. Pulmonary endarterectomy: recent changes in a single institution's experience of more than 2,700 patients. Ann Thorac Surg. 2012;94:97-103.

4. Madani M, Mayer E, Fadel E, Jenkins DP. Pulmonary endarterectomy. Patient selection, technical challenges, and outcomes. Ann Am Thorac Soc. 2016;13(Suppl 3):S240-7.

5. Ogawa A, Satoh T, Fukuda T, Sugimura K, Fukumoto Y, Emoto N, et al. Balloon angioplasty for chronic thromboembolic pulmonary hypertension: results of a multicenter registry. Circ Cardiovasc Qual Outcomes. 2017;10:e004029.
See Article page 696.

\section{Commentary: Segmental pulmonary endarterectomy: Going out on the limb}

\author{
Cameron D. Wright, MD
}

De Perrot and colleagues ${ }^{1}$ report a large series of pulmonary endarterectomies (PEAs), emphasizing the excellent results that were achieved in patients with segmental disease $(2.8 \%$ operative mortality). Patients with segmental disease are technically more challenging (note the longer circulatory arrest times, intensive care unit stay, and hospital stay), but despite the surgical challenge the results were essentially the same as those with more proximal disease. The reason why segmental disease rose from $7 \%$ to $41 \%$ in their last cohort is not discussed, but I postulate that this was due to an increased surgical confidence in tackling more difficult patients. Their center is a highvolume center of excellence with a nationwide referral pattern that represents the ideal paradigm to treat this complex disease. That preoperative medical therapy is a risk factor for a worse result in segmental disease is intriguing and has important clinical implications. I agree with their recommendation that prompt referral to an

\footnotetext{
From the Division of Thoracic Surgery, Massachusetts General Hospital, Boston, Mass.

Disclosures: Dr Wright is a consultant for Bayer.

The Journal policy requires editors and reviewers to disclose conflicts of interest and to decline handling or reviewing manuscripts for which they may have a conflict of interest. The editors and reviewers of this article have no conflicts of interest.

Received for publication Nov 8, 2021; revisions received Nov 8, 2021; accepted for publication Nov 8, 2021; available ahead of print Nov 13, 2021.

Address for reprints: Cameron D. Wright, MD, Division of Thoracic Surgery, Massachusetts General Hospital, Austen 7, 55 Fruit St, Boston, MA 02114 (E-mail: wright.cameron@mgh.harvard.edu).

J Thorac Cardiovasc Surg 2022;164:709-10

$0022-5223 / \$ 36.00$

Copyright (c) 2021 by The American Association for Thoracic Surgery

https://doi.org/10.1016/j.jtcvs.2021.11.019
}

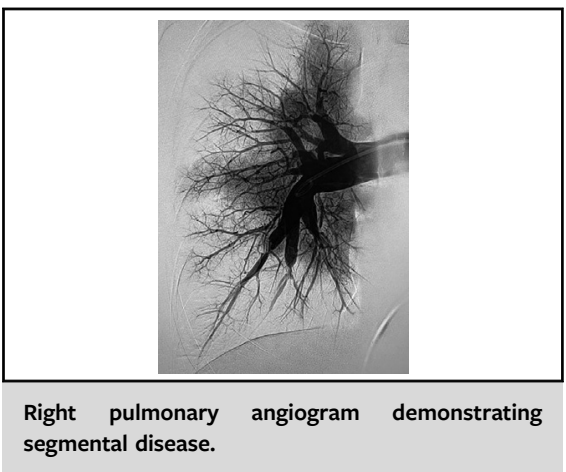

CENTRAL MESSAGE

The early results of PEA in segmental CTEPH are essentially equivalent to more proximal disease, but at 10 years many segmental patients require medical therapy for residual pulmonary hypertension.

experienced chronic thromboembolic pulmonary hypertension (CTEPH) center once the diagnosis is suspected or confirmed before initiation of medical therapy is prudent. An early decision favoring an operative approach may obviate the development of distal vasculopathy and the need for later medical therapy. This concept is opposite that of the current balloon pulmonary angioplasty (BPA) paradigm where many now favor medical therapy to reduce pulmonary artery pressure in patients with high pulmonary artery pressure to reduce procedurerelated complications.

Of particular importance in this study is the long-term follow-up facilitated by the close collaboration with referring physicians. It is challenging to obtain long-term clinical follow-up in CTEPH patients because they typically 